\title{
Pregnancy outcomes of single/double blastocysts and cleavage embryo transfers: A retrospective cohort study of 24422 frozen-thawed cycles
}

\author{
Xiaoyu Long ${ }^{1}$, Yuanyuan Wang ${ }^{1}$, Fangrong $\mathrm{Wu}^{1}$, Rong $\mathrm{Li}^{1}$, Chen Lixue ${ }^{1}$, Weiping Qian ${ }^{1}$, \\ and Jie Qiao ${ }^{2}$ \\ ${ }^{1}$ Affiliation not available \\ ${ }^{2}$ Peking University Third Hospital
}

May 5, 2020

\begin{abstract}
Objective: This study aims to provide an evidence-based assessment of the benefits and harms of four transplantation methods so as to improve the superior pregnancy outcome and reduce the pregnancy rate of multiple embryos in the Mongoloid race. Design: Retrospective analysis Setting: Double Reproductive Centers of Medical University Population or Sample: 24,422 frozen-thawed embryo transfer (FET) cycles recorded from January 2015 to May 2018. Methods:A retrospective cohort study Main Outcome Measures: Biochemical pregnancy, clinical pregnancy, monozygotic twins, miscarriage, maternal complications, live birth. Results: Of the four groups, the biochemical pregnancy rate, the clinical pregnancy rate, and the live birth rate were the lowest in the C-1 group while they were the highest in the B-2 group. However, the B-2 group was accompanied with higher risks of miscarriage, maternal complications, twin births, preterm births and low birth weights. The biochemical pregnancy rates, the clinical pregnancy rates and the live birth rates in the C-2 group and B-1 group were statistically different, with different risks for monozygotic twins, miscarriages. Conclusion: Single blastocyst transplantation seems to be the best choice for all maternal ages to greatly reduce adverse neonatal outcomes. Tweetable abstract: This was a retrospective cohort study using the ART databases from two affiliated hospitals of Peking University. 24,422 frozen-thawed embryo transfer (FET) cycles recorded from January 2015 to May 2018 were selected to generate the research database which also included maternal characteristics.
\end{abstract}

\section{Tweetable abstract:}

This was a retrospective cohort study using the ART databases from two affiliated hospitals of Peking University. 24,422 frozen-thawed embryo transfer (FET) cycles recorded from January 2015 to May 2018 were selected to generate the research database which also included maternal characteristics.

\section{Fundings:}

Research Team of Female Reproductive Health and Fertility Preservation (SZSM201612065)

National Natural Science Foundation of China-Youth Foundation (No.81401169)

Beijing Municipal Science \& Technology Commission (No. Z191100006619086).

Keywords: transfer strategy, double embryo transfer, single blastocyst transfer

\section{Introduction:}

It has been over 40 years since the development of assisted reproductive technology. With the improvements of assisted reproductive technologies such as ovulation induction, embryo culture and vitrification, and other 
technologies, experts in the field of reproductive medicine are no longer only concerned about pregnancy rates, but of delivering healthy live births. At present, the most common clinical transfer strategies include twin embryo and single blastocyst transfer. In addition, single embryo and double blastocyst transfer will also be performed in the clinic under certain conditions. How to choose a way that can ensure the success rate of transplantation and reduce the incidence of complications to the greatest extent is the focus of clinicians. Different transplantation methods may have different outcomes in different countries and races ${ }^{1,2}$. In order to study the advantages and disadvantages of these four transplantation methods, we selected two large reproductive medical centers, one in Beijing and the other in Shenzhen, to represent the northern and southern regions of China respectively. The majority of individuals in China belong to the Mongoloid race. This study aims to provide an evidence-based assessment of the benefits and harms of four transplantation methods so as to improve the superior pregnancy outcome and reduce the pregnancy rate of multiple embryos in the Mongoloid race.

\section{Methods}

\section{Data source and variables}

This was a retrospective cohort study that used the ART databases from two affiliated hospitals of Peking University (Peking University Third Hospital and Peking University Shenzhen Hospital). 24,422 frozenthawed embryo transfer (FET) cycles recorded from January 2015 to May 2018 were selected to generate the research database. The database included the following; maternal characteristics (maternal age at treatment, height, weight, infertility type, cause of infertility and duration of infertility, and number of previous ART cycles), treatment records of the current cycle (type of fertilization in the current cycle, numbers of embryo transferred, days of embryo development), maternal outcomes (biochemical pregnancy, clinical pregnancy, monozygotic twins, miscarriages, and maternal complications) and neonatal outcomes (live births, number of live births, gestational age at delivery, birth weight, and congenital malformations).

Of the 24,422 FET cycles, 440 preimplantation genetic analysis (PGA) cycles, 42 in vitro maturation (IVM) cycles, 3 assisted oocyte activation (AOA) cycles, 13 cycles with missing values in numbers of embryo transferred, 6 cycles with missing values in days of embryo development, 20 cycles with two embryos in different development days and 172 cycles with loss to follow-up were excluded from the analysis. Finally, 23,726 cycles were included for the final analysis. This included 13,767 cleavage-stage embryo transfer cycles $(58.0 \%)$ and 9,959 blastocyst-stage embryo transfer cycles $(42.0 \%)$. Based on the stage (cleavage-stage or blastocyst-stage) and number (one or two) of embryos transferred, all the selected cycles were divided into four exposure groups: the single cleavage-stage embryo transfer group (C-1) (763 cycles, 3.2\%), double cleavage-stage embryo transfer group (C-2) (13004 cycles, 58.0\%), single blastocyst-stage embryo transfer group (B-1) (7913 cycles, 33.4\%) and double blastocyst-stage embryo transfer group (B-2) (2046 cycles, $8.6 \%$ ). (Figure 1)

The following data were analyzed for each cycle: maternal age (20-29 years, 30-34 years, 35-37 years, 38-39 years, 40-42 years, or $>42$ years), body mass index (BMI) (equal to height/weight2 (m/kg2), BMI $<18.5$ defined as 'underweight', 18.5[?]BMI $<24$ defined as 'fitting', 24[?]BMI $<27$ defined as 'overweight', or BMI[?]27 defined as 'obesity'), infertility type (primary infertility, or secondary infertility), cause of infertility (tubal, ovulatory, endometriosis, male factor, or unexplained), duration of infertility ([?]4 years or $>4$ years), type of fertilization in the current cycle (IVF, ICSI, or IVF+ICSI), previous ART cycles (0-1 cycles, 2-3 cycles, 4-5 cycles, or [?]6 cycles), biochemical pregnancy (yes or no), clinical pregnancy (yes or no), monozygotic twins (yes or no), miscarriage (yes or no), maternal complications (yes or no), live birth (yes or no), twin birth (yes or no), preterm birth (defined as 'gestational week at delivery $<37$ weeks, yes or no), low birth weight (defined as 'birth weight at delivery $<2500$ grams', yes or no), small for gestational age infant (SGA, defined as 'birth weight at delivery $<10$ th percentile for the baby's gender and gestational age, using Chinese reference charts' ${ }^{3}$, yes or no), and congenital malformations (yes or no). With regards to cycles with multiple pregnancies or births, the cycle was defined as "yes" for live births, preterm births, low birth weights, SGA or congenital malformations. 
The study was approved by the Peking University Third Hospital Medical Science Research Ethics Committee (IRB00006761-M2019107).

\section{Statistical analysis}

Comparisons among all the four groups or between any two groups were performed using the $\chi^{2}$ test (Pearson Chi-square for cases where none of the cells has expected counts less than 5; Likelihood Ratio for cases with one or more cells had expected counts less than 5). $\mathrm{P}<0.05$ was considered statistically significant for comparisons among all four groups and $\mathrm{P}<0.008$ was considered statistically significant for comparisons between any two groups, where Bonferroni-corrected p-value was used for multiple pairwise comparisons (the alpha-level was divided by the number of pairwise comparisons, the number of pairwise comparisons for all four groups was 6 , i.e., equal to $0.05 / 6)^{4}$.

In addition, comparisons between the double cleavage-stage embryo transfer group (C-2) and the single blastocyst-stage embryo transfer group (B-1) were performed. First, unadjusted logistic regressions were performed to calculate unadjusted odds ratios (ORs) and 95\% confidence intervals (CIs) of B-1 VS C-2 for each maternal or neonatal outcome. Then, multivariable logistic regressions were performed to calculate adjusted odds ratios (aORs) and 95\% CIs, which included maternal age, BMI, infertility type, cause of infertility, duration of infertility, type of fertilization in the current cycle, and previous ART cycles. Furthermore, multivariable logistic regression models were used to predict absolute risks (probabilities) for each maternal or neonatal outcome for each maternal age group. This was graphically presented to illustrate age-outcome relationships.

All analyses were performed using IBM SPSS Statistics 25.0 (Armonk, NY: IBM Corp.).

\section{Results}

\section{Maternal characteristics}

A total of 23726 FET cycles were included in this study, of which, 763 cycles were single cleavage-stage embryo transfers (C-1 group), 13004 were double cleavage-stage embryo transfers (C-2 group), 7913 were single blastocyst-stage embryo transfers (B-1 group), and 2046 were double blastocyst-stage embryo transfers (B-2 group). Maternal characteristics for all FET cycles and for each group are summarized in Table 1. Maternal characteristics among the four groups were statistically different for maternal age, BMI, infertility type, cause of infertility, duration of infertility, type of fertilization in the current cycle, and previous ART cycles $(\mathrm{P}<0.05)$. Results of pairwise comparisons of maternal characteristics between the groups are shown in Table S1.

\section{Maternal and neonatal outcomes for the different transfer strategies}

Maternal and neonatal outcomes for all FET cycles and in each group are summarized in Table 1. Maternal and neonatal outcomes for the four groups were statistically different for biochemical pregnancy, clinical pregnancy, monozygotic twins, miscarriages, maternal complications, live births, twin births, preterm births, low birth weight and SGA $(\mathrm{P}<0.05)$. Results of pairwise comparisons for maternal and neonatal outcomes between the groups are shown in Table S1. Percentages for each maternal or neonatal outcomes for each group are shown in Figure 2.

Among the four groups, the biochemical pregnancy rate, the clinical pregnancy rate, and the live birth rate were the lowest in the C-1 group $(24.1 \%, 21.5 \%$ and $11.8 \%$, respectively) and were the highest in the B-2 group (59.1\%, $53.0 \%$ and $33.6 \%$, respectively). However, this was accompanied with higher risks of miscarriages $(21.2 \%)$, maternal complications (11.9\%), twin births (28.9\%), preterm births (21.2\%) and low birth weight $(17.7 \%)(\mathrm{P}<0.008$, Bonferroni-corrected p-value for multiple pairwise comparisons). The biochemical pregnancy rates, the clinical pregnancy rates and the live birth rates in the C-2 group and B-1 group were statistically different ( $46.7 \%$ vs $50.0 \%, 42.1 \%$ vs $44.3 \%, 29.0 \%$ vs $23.0 \%$, respectively), with different risks for monozygotic twins, miscarriages, twin births, preterm births, low birth weights and SGA $(\mathrm{P}<0.008)$. These results demonstrated that the double cleavage-stage embryo transfer strategy and the 
single blastocyst-stage embryo transfer strategy were preferential among the four groups. Hence additional comparisons between the C-2 and B-1 groups were performed.

In this study, 20 cases $(0.3 \%)$ of congenital malformations were reported among live births and included one case $(1.1 \%)$ in the $\mathrm{C}-1$ group, 12 cases $(0.3 \%)$ in the C-2 group, 6 cases $(0.3 \%)$ in the B-1 group, and one case $(0.1 \%)$ in the B-2 group. However, due to the limited sample size, comparisons of congenital malformations between the groups were not performed.

In addition, comparisons were performed between the double-cleavage transfer (C-2) and the single-blastocyst transfer (B-1) group. After adjusting for maternal age, BMI, infertility type, cause of infertility, duration of infertility, type of fertilization in the current cycle and previous ART cycles, the biochemical pregnancy rates and the clinical pregnancy rates between two groups were not statistically different (aOR for the biochemical pregnancy rate, 1.07; 95\% CI, 1.00-1.15; and aOR for the clinical pregnancy rate, 1.04; 95\% CI, 0.97-1.12); and the live birth rate in the B-1 group was lower compared to the C-2 group (aOR, 0.78; 95\% CI, 0.720.85 ). With regards to negative outcomes, compared to the C-2 group, the B-1 group had a higher risk for monozygotic twins (aOR, 3.02; 95\% CI, 1.79-5.10) and miscarriages (aOR, 1.29; 95\% CI, 1.11-1.51) but had a lower risk for twin births (aOR, 0.06; 95\% CI, 0.04-0.09), preterm births (aOR, 0.51; 95\% CI, 0.41-0.65), low birth weights (aOR, 0.30; 95\% CI, 0.22-0.40) and SGA (aOR, 0.51; 95\% CI, 0.33-0.77)(.

Maternal age is often considered as one of the most important determinants for maternal and neonatal outcomes for any type of ART cycle. Therefore, maternal or neonatal outcomes between the C-2 group and B-1 group and probabilities for each maternal age group (20-29 years old, 30-34 years old, 35-37 years old, 38-39 years old, 40-42 years old and $>42$ years old) were calculated. Results are shown in Figure 3 (Detailed results are shown in Table S2 and Table S3).

With regards to the C-2 group, the probability of biochemical pregnancy and clinical pregnancy declined from 0.55 and 0.50 at $20-29$ years old to 0.27 and 0.22 at $>40$ years old. Of the cycles with clinical pregnancy, the probability of monozygotic twins decreased from 0.008 to 0.005 , the probability of miscarriages increased from 0.11 to 0.31 and the probability of maternal complications increased from 0.09 to 0.20 at the same maternal age intervals. The probability of live birth declined from 0.30 at $20-29$ years old to 0.11 at $>40$ years old. Among those cycles with live births, the probability of twin births declined from 0.28 to 0.11 , and the probabilities of preterm births, low birth weights, and SGA slightly fluctuated from 0.14 to $0.18,0.12$ to 0.15 and 0.05 to 0.06 , respectively. (Detailed results are shown in Table S4).

With regards to the B-1 group, the probability of biochemical pregnancy and clinical pregnancy declined from 0.56 and 0.51 at 20-29 years old to 0.28 and 0.22 at $>40$ years old. Among those cycles with clinical pregnancy, the probability of monozygotic twins decreased from 0.023 to 0.011 , the probability of miscarriages increased from 0.13 to 0.34 and the probability of maternal complications increased from 0.08 to 0.16 at the same maternal age intervals. The probability of live birth declined from 0.25 at $20-29$ years old to 0.08 at $>40$ years old. Among the cycles with live births, the probability of twin births, preterm births, low birth weight, and SGA slightly fluctuated from 0.01 to $0.02,0.07$ to $0.10,0.04$ to 0.05 and 0.02 to 0.03 , respectively.

\section{Discussion}

\section{Main Findings}

During the IVF-ET process, in order to attain a higher clinical pregnancy rate, the strategy of twin embryo transfers are implemented. However, using this strategy also increases the probability of multiple pregnancies ${ }^{1,5,6}$. Multiple pregnancy is a serious complication encountered during assisted reproductivity. It can increase the incidence of abortions, fetal deaths, fetal malformations, fetal intrauterine growth restrictions, and the incidence of pregnancy complications such as maternal anemia and pregnancy-induced hypertension compared to single pregnancy ${ }^{5-9}$.

In order to reduce the occurrence of multiple pregnancies, the number of embryos transferred should be reduced. However, this could reduce the pregnancy rate. How to reduce the number of transferred embryos 
without affecting the pregnancy rate is important for the success of assisted reproductive technology. Although single embryo transfer logically reduces multiple pregnancies, the clinical pregnancy rate and live birth rate of single embryo transfer are significantly reduced in older women. Hence, single embryo transfers are rarely used in clinical practice. Several studies have shown that the implantation rate and clinical pregnancy rate of blastocyst transfer are higher compared to cleavage embryo transfer, while the rate of multiple pregnancies and ovarian hyperstimulation are lower ${ }^{10-12}$. Previous studies have compared the clinical outcomes of twin embryo transfer and single blastocyst transfer. However, these were small cohort studies that were not segregated into the four different transfer groups or segregated based on age ${ }^{13,14}$. Hence, we analyzed a very large sample cohort derived from our two centers and divided them into the following four groups: single embryo transfer, double embryo transfer, single blastocyst transfer and double blastocyst transfer groups. We compared their clinical pregnancy rate and perinatal outcome and stratified them based on the age of the patient.

Our results demonstrated that the biochemical pregnancy rate, clinical pregnancy rate and live birth rate in the single embryo transfer group were significantly lower compared to the other three groups, while the abortion rate was significantly higher. The biochemical pregnancy rate, clinical pregnancy rate and live birth rate of the double blastocyst transplantation group were significantly higher compared to the other three groups and were statistically different. However, the twin pregnancy rate and the incidence of maternal and fetal complications were the highest. Hence, we do not recommend these two transplantation strategies. This is consistent with the current clinical choice.

We then compared the twin embryo transfer group with the single blastocyst transfer group. We found no significant differences in biochemical pregnancy rate and clinical pregnancy rate between the two groups, however, the live birth rate in the twin embryo transfer group was higher compared to the single blastocyst transfer group, while the twin pregnancy rate, premature delivery rate, low birth weight rate and SGA in the twin embryo transfer group were significantly higher compared to the single blastocyst transfer group. This does not support our intention to deliver healthy babies. In order to reduce the incidence of maternalfetal complications and multiple pregnancies, single blastocyst transplantation strategy seems to be the best choice. This may be because blastocyst transfer is more in line with the physiological environment compared to cleavage embryo transfer. This is because under natural physiological conditions, the cleavage embryo develops in the fallopian tube and does not enter the uterine cavity until the blastocyst stage. In addition, endometrium and embryo development are more synchronous and is more conducive to embryo implantation. There is no screening during embryo to blastocyst stage culture, with only good quality embryos developing to the blastocyst stage.

Maternal age is an important factor for the outcome of assisted reproductive technology ${ }^{15-17}$, hence we grouped patients based on age. We found that in the different age groups, the biochemical pregnancy rate and clinical pregnancy rate of single blastocyst transplantation were slightly higher compared to double embryo transplantation, while the live pregnancy rate was slightly lower compared to double embryo transplantation. With the increase in age, the biochemical pregnancy rate, clinical pregnancy rate and live birth rate for the two groups had a downward trend. In the $>42$ age group, the live birth rate for single blastocyst embryo transfer was only $8 \%$, while it was only $11 \%$ for the double embryo transfer group. The miscarriage rate increased significantly with the increase in age. For the age group over 42 years old, the miscarriage rate in the double embryo transfer group was $31 \%$, while it was $34 \%$ in the single blastocyst transfer group. The rate of maternal complications increased significantly with the increase in age. For the age group over 42 years old, the rate of maternal complications was $20 \%$ in the double embryo transfer group, while wit was $16 \%$ in the single blastocyst transfer group. What's more, it seemed that the single blastocyst transfer group was more likely to result in monozygotic twins than the double embryo transfer group, and the rate of monozygotic twins in both of two groups decreased with the increase of age. In addition, there were no significant changes in the birth rates of preterm birth, low birth weight and SGA with an increase in age, however, the birth rate of preterm birth, low birth weight and SGA in the twin embryo transfer group was significantly higher compared to the single blastocyst transfer group for all ages. 


\section{Strengths and Limitations}

Our study has some limitations, because it is not a randomized controlled study, and only two units are included. Therefore, we are going to expand the research scope and set up randomized controlled study in the future, which may have a better guiding role in clinical practice.

\section{Conclusion}

In summary, single blastocyst transplantation seems to be the best choice for all maternal ages to greatly reduce adverse neonatal outcomes (twin birth, preterm birth, low birth weight and SGA), although slightly compromising to increasing in monozygotic twins and miscarriage and reducing in live birth. Doctors should select the most suitable transplantation strategy based on the patient's situation. However, with advances in reproductive medicine, single blastocyst transplantation may be the optimal choice for women who desire to get pregnant and deliver a healthy baby.

\section{Acknowledgements}

This work was supported by the Research Team of Female Reproductive Health and Fertility Preservation (SZSM201612065), National Natural Science Foundation of China-Youth Foundation (No.81401169), Beijing Municipal Science \& Technology Commission (No. Z191100006619086), National Key Research and Development Program of China (No. 2016YFC1000201) and The capital health research and development of special (No. 2018-1-4091). The study funders had no rule in the study design, implementation, analysis, manuscript, preparation, or decision to submit this article for publication.

\section{Disclosure of Interests}

None declared.

\section{Contribution to Authorship}

X.L and Y.W. was mainly in charge of data analysis and drafting the article. F.W. contributed to the acquisition of Shenzhen's data, and revising the article for important intellectual content. R.L. contributed to draft and revise the article. L.C. contributed to the acquisition of Beijing's data. J.Q. and W.Q. contributed to conception and design, final approval of the version to be published as corresponding author.

\section{Details of Ethics Approval}

The study protocol was approved by the Peking University Third Hospital Medical Science Research Ethics Committee (IRB00006761-M2019107). The date of approval is October 7, 2019. Informed consent was obtained from every participant accepted our survey.

\section{References:}

1. Glujovsky D, Farquhar C. Cleavage-stage or blastocyst transfer: what are the benefits and harms? Fertility and sterility. 2016;106(2):244-50.

2. Martins WP, Nastri CO, Rienzi L, van der Poel SZ, Gracia CR, Racowsky C. Obstetrical and perinatal outcomes following blastocyst transfer compared to cleavage transfer: a systematic review and meta-analysis. Human reproduction. 2016;31(11):2561-9.

3. Zhu L, Zhang R, Zhang S, Shi W, Yan W, Wang X, et al. [Chinese neonatal birth weight curve for different gestational age]. Zhonghua er ke za zhi = Chinese journal of pediatrics. 2015;53(2):97-103.

4. Bland JM, Altman DG. Multiple significance tests: the Bonferroni method. Bmj. 1995;310(6973):170.

5. Qin JB, Sheng XQ, Wang H, Chen GC, Yang J, Yu H, et al. Worldwide prevalence of adverse pregnancy outcomes associated with in vitro fertilization/intracytoplasmic sperm injection among multiple births: a systematic review and meta-analysis based on cohort studies. Archives of gynecology and obstetrics. 2017;295(3):577-97. 
6. Moini A, Shiva M, Arabipoor A, Hosseini R, Chehrazi M, Sadeghi M. Obstetric and neonatal outcomes of twin pregnancies conceived by assisted reproductive technology compared with twin pregnancies conceived spontaneously: a prospective follow-up study. European journal of obstetrics, gynecology, and reproductive biology. 2012;165(1):29-32.

7. Busnelli A, Dallagiovanna C, Reschini M, Paffoni A, Fedele L, Somigliana E. Risk factors for monozygotic twinning after in vitro fertilization: a systematic review and meta-analysis. Fertility and sterility. 2019;111(2):302-17.

8. Tan J, Qi YN, Zhang J, Wang W, Zhang GT, Zou K, et al. The mediation effect of multiple gestations on the association between in vitro fertilisation and severe maternal morbidities: a retrospective cohort study. BMJ open. 2019;9(7):e022670.

9. Le Ray C, Pelage L, Seco A, Bouvier-Colle MH, Chantry AA, Deneux-Tharaux C, et al. Risk of severe maternal morbidity associated with in vitro fertilisation: a population-based study. BJOG : an international journal of obstetrics and gynaecology. 2019;126(8):1033-41.

10. Marek D, Langley M, Gardner DK, Confer N, Doody KM, Doody KJ. Introduction of blastocyst culture and transfer for all patients in an in vitro fertilization program. Fertility and sterility. 1999;72(6):1035-40.

11. Evans J, Hannan NJ, Edgell TA, Vollenhoven BJ, Lutjen PJ, Osianlis T, et al. Fresh versus frozen embryo transfer: backing clinical decisions with scientific and clinical evidence. Human reproduction update. 2014;20(6):808-21.

12. Glujovsky D, Blake D, Farquhar C, Bardach A. Cleavage stage versus blastocyst stage embryo transfer in assisted reproductive technology. The Cochrane database of systematic reviews. 2012(7):CD002118.

13. Glujovsky D, Farquhar C, Quinteiro Retamar AM, Alvarez Sedo CR, Blake D. Cleavage stage versus blastocyst stage embryo transfer in assisted reproductive technology. The Cochrane database of systematic reviews. 2016(6):CD002118.

14. Martins WP, Nastri CO, Rienzi L, van der Poel SZ, Gracia C, Racowsky C. Blastocyst vs cleavage-stage embryo transfer: systematic review and meta-analysis of reproductive outcomes. Ultrasound in obstetrics \& gynecology : the official journal of the International Society of Ultrasound in Obstetrics and Gynecology. 2017;49(5):583-91.

15. Tannus S, Son WY, Dahan MH. Elective single blastocyst transfer in advanced maternal age. Journal of assisted reproduction and genetics. 2017;34(6):741-8.

16. Harrison BJ, Hilton TN, Riviere RN, Ferraro ZM, Deonandan R, Walker MC. Advanced maternal age: ethical and medical considerations for assisted reproductive technology. International journal of women's health. 2017;9:561-70.

17. Moaddab A, Chervenak FA, McCullough LB, Sangi-Haghpeykar H, Shamshirsaz AA, Schutt A, et al. Effect of advanced maternal age on maternal and neonatal outcomes in assisted reproductive technology pregnancies. European journal of obstetrics, gynecology, and reproductive biology. 2017;216:178-83.

\section{Figure legends}

Figure 1 Flow chart showing the data selection process for analysis in this study

Figure 2 Percentages of each maternal or neonatal outcome in each group

Notes: C-2 indicates the double cleavage-stage embryo transfer group; B-1 indicates the single blastocyststage embryo transfer group. * The denominator is the number of clinical pregnancies in each group. [?] The denominator is the number of live births in each group.

Figure 3 Probabilities of each maternal or neonatal outcome in each maternal age group 
Notes: C-2 indicates the double cleavage-stage embryo transfer group; B-1 indicates the single blastocyststage embryo transfer group. * The denominator is the number of clinical pregnancies in each group. [?] The denominator is the number of live births in each group. The probabilities of each maternal or neonatal outcome in each maternal age group were calculated by using the model of multivariable logistic regressions.

Table 1.

Description and comparison of maternal characteristics, maternal and neonatal outcomes among all of four groups

\begin{tabular}{|c|c|c|c|c|c|c|c|}
\hline & $\begin{array}{l}\text { All FET } \\
\text { cycles } \\
(n=23726)\end{array}$ & $\begin{array}{l}\text { Single } \\
\text { cleavage- } \\
\text { stage } \\
\text { embryo } \\
\text { transfer } \\
\text { group } \\
(\mathrm{C}-1) \\
(\mathrm{n}=763) \\
\end{array}$ & $\begin{array}{l}\text { Double } \\
\text { cleavage- } \\
\text { stage } \\
\text { embryo } \\
\text { transfer } \\
\text { group } \\
(\mathrm{C}-2) \\
(\mathrm{n}=13004) \\
\end{array}$ & $\begin{array}{l}\text { Single } \\
\text { blastocyst- } \\
\text { stage } \\
\text { embryo } \\
\text { transfer } \\
\text { group } \\
(\mathrm{B}-1) \\
(\mathrm{n}=7913)\end{array}$ & $\begin{array}{l}\text { Double } \\
\text { blastocyst- } \\
\text { stage } \\
\text { embryo } \\
\text { transfer } \\
\text { group } \\
(\mathrm{B}-2) \\
(\mathrm{n}=2046)\end{array}$ & $\mathrm{X}^{2}$ & $\mathbf{P}$ \\
\hline \multicolumn{8}{|l|}{$\begin{array}{l}\text { Maternal } \\
\text { Charac- } \\
\text { teristics }\end{array}$} \\
\hline $\begin{array}{l}\text { Maternal } \\
\text { age } \\
\text { (years) }\end{array}$ & $32(29,35)$ & $34(31,39)$ & $32(29,35)$ & $32(29,35)$ & $32(29,35)$ & & \\
\hline $20-29$ & $\begin{array}{l}7269 \\
(30.6)\end{array}$ & $129(16.9)$ & $\begin{array}{l}4107 \\
(31.6)\end{array}$ & $\begin{array}{l}2417 \\
(30.5)\end{array}$ & $616(30.1)$ & 520.688 & $<0.001$ \\
\hline $30-34$ & $\begin{array}{l}9640 \\
(40.6)\end{array}$ & $257(33.7)$ & $\begin{array}{l}5289 \\
(40.7)\end{array}$ & $\begin{array}{l}3217 \\
(40.7)\end{array}$ & $877(42.9)$ & & \\
\hline $35-37$ & $\begin{array}{l}3790 \\
(16.0)\end{array}$ & $132(17.3)$ & $\begin{array}{l}1956 \\
(15.0)\end{array}$ & $\begin{array}{l}1367 \\
(17.3)\end{array}$ & $335(16.4)$ & & \\
\hline 38-39 & $1297(5.5)$ & $75(9.8)$ & $644(5.0)$ & $464(5.9)$ & $114(5.6)$ & & \\
\hline $40-42$ & $1084(4.6)$ & $71(9.3)$ & $603(4.6)$ & $329(4.2)$ & $81(4.0)$ & & \\
\hline$>42$ & $646(2.7)$ & $99(13.0)$ & $405(3.1)$ & $119(1.5)$ & $23(1.1)$ & & \\
\hline $\begin{array}{l}\text { Body } \\
\text { Mass }\end{array}$ & $\begin{array}{l}21.6(19.8, \\
24.0)\end{array}$ & $\begin{array}{l}21.5(19.6, \\
23.9)\end{array}$ & $\begin{array}{l}21.5(19.6, \\
23.7)\end{array}$ & $\begin{array}{l}22.0(20.0 \\
24.4)\end{array}$ & $\begin{array}{l}21.5(19.7, \\
23.8)\end{array}$ & & \\
\hline $\begin{array}{l}\text { Index } \\
(\mathrm{BMI})\end{array}$ & & & & & & & \\
\hline $\begin{array}{l}\text { Underweight } \\
(\mathrm{BMI}<18.5)\end{array}$ & $1914(8.1)$ & $62(8.1)$ & $1128(8.7)$ & $554(7.0)$ & $170(8.3)$ & 87.861 & $<0.001$ \\
\hline $\begin{array}{l}\text { Fitting } \\
(18.5[?] \mathrm{BMI}<2\end{array}$ & $\begin{array}{r}11474 \\
4(48.4)\end{array}$ & $338(44.3)$ & $\begin{array}{l}6259 \\
(48.1)\end{array}$ & $\begin{array}{l}3862 \\
(48.8)\end{array}$ & $\begin{array}{l}1015 \\
(49.6)\end{array}$ & & \\
\hline $\begin{array}{l}\text { Overweight } \\
(24[?] \mathrm{BMI}<27)\end{array}$ & $\begin{array}{l}2940 \\
(12.4)\end{array}$ & $84(11.0)$ & $\begin{array}{l}1480 \\
(11.4)\end{array}$ & $\begin{array}{l}1132 \\
(14.3)\end{array}$ & $244(11.9)$ & & \\
\hline $\begin{array}{l}\text { Obesity } \\
\text { (BMI[?]27) }\end{array}$ & $1571(6.6)$ & $39(5.1)$ & $744(5.7)$ & $654(8.3)$ & $134(6.5)$ & & \\
\hline $\begin{array}{l}\text { Missing } \\
\text { value } \\
\text { Infertility } \\
\text { type }\end{array}$ & $\begin{array}{l}5827 \\
(24.6)\end{array}$ & $240(31.5)$ & $\begin{array}{l}3393 \\
(26.1)\end{array}$ & $\begin{array}{l}1711 \\
(21.6)\end{array}$ & $483(23.6)$ & & \\
\hline $\begin{array}{l}\text { Primary } \\
\text { infertility }\end{array}$ & $\begin{array}{l}14463 \\
(61.0)\end{array}$ & $402(52.7)$ & $\begin{array}{l}8034 \\
(61.8)\end{array}$ & $\begin{array}{l}4731 \\
(59.8)\end{array}$ & $\begin{array}{l}1296 \\
(63.3)\end{array}$ & 33.535 & $<0.001$ \\
\hline
\end{tabular}




\begin{tabular}{|c|c|c|c|c|c|c|c|}
\hline & $\begin{array}{l}\text { All FET } \\
\text { cycles } \\
(\mathrm{n}=23726)\end{array}$ & $\begin{array}{l}\text { Single } \\
\text { cleavage- } \\
\text { stage } \\
\text { embryo } \\
\text { transfer } \\
\text { group } \\
(\mathrm{C}-1) \\
(\mathrm{n}=763)\end{array}$ & $\begin{array}{l}\text { Double } \\
\text { cleavage- } \\
\text { stage } \\
\text { embryo } \\
\text { transfer } \\
\text { group } \\
(\mathrm{C}-2) \\
(\mathrm{n}=13004)\end{array}$ & $\begin{array}{l}\text { Single } \\
\text { blastocyst- } \\
\text { stage } \\
\text { embryo } \\
\text { transfer } \\
\text { group } \\
(\mathrm{B}-1) \\
(\mathrm{n}=7913)\end{array}$ & $\begin{array}{l}\text { Double } \\
\text { blastocyst- } \\
\text { stage } \\
\text { embryo } \\
\text { transfer } \\
\text { group } \\
(\mathrm{B}-2) \\
(\mathrm{n}=2046)\end{array}$ & $\mathrm{X}^{2}$ & $\mathbf{P}$ \\
\hline $\begin{array}{l}\text { Secondary } \\
\text { infertility }\end{array}$ & $\begin{array}{l}9026 \\
(38.0)\end{array}$ & $343(45.0)$ & $\begin{array}{l}4828 \\
(37.1)\end{array}$ & $\begin{array}{l}3125 \\
(39.5)\end{array}$ & $730(35.7)$ & & \\
\hline $\begin{array}{l}\text { Missing } \\
\text { value } \\
\text { Cause of } \\
\text { infertility }\end{array}$ & $237(1.0)$ & $18(2.4)$ & $142(1.1)$ & $57(0.7)$ & $20(1.0)$ & & \\
\hline Tubal & $\begin{array}{l}8730 \\
(36.8)\end{array}$ & $259(33.9)$ & $\begin{array}{l}5075 \\
(39.0)\end{array}$ & $\begin{array}{l}2539 \\
(32.1)\end{array}$ & 857 (41.9) & 128.751 & $<0.001$ \\
\hline Ovulatory & $\begin{array}{l}5575 \\
(23.5)\end{array}$ & $201(26.3)$ & $\begin{array}{l}3019 \\
(23.2)\end{array}$ & $\begin{array}{l}1801 \\
(22.8)\end{array}$ & $554(27.1)$ & 20.990 & $<0.001$ \\
\hline Endometriosis & $1455(6.1)$ & $65(8.5)$ & $835(6.4)$ & $440(5.6)$ & $115(5.6)$ & 14.860 & 0.002 \\
\hline $\begin{array}{l}\text { Male } \\
\text { factor }\end{array}$ & $\begin{array}{l}9023 \\
(38.0)\end{array}$ & $261(34.2)$ & $\begin{array}{l}5025 \\
(38.6)\end{array}$ & $\begin{array}{l}3018 \\
(38.1)\end{array}$ & $719(35.1)$ & 14.081 & 0.003 \\
\hline Unexplained & $\begin{array}{l}5136 \\
(21.6)\end{array}$ & $183(24.0)$ & $\begin{array}{l}2456 \\
(18.9)\end{array}$ & $\begin{array}{l}2138 \\
(27.0)\end{array}$ & $359(17.5)$ & 215.792 & $<0.001$ \\
\hline $\begin{array}{l}\text { Duration } \\
\text { of } \\
\text { infertility } \\
\text { (years) }\end{array}$ & $4(2,6)$ & $4(2,6)$ & $4(2,6)$ & $4(2,6)$ & $4(2,6)$ & & \\
\hline$[?] 4$ & $\begin{array}{l}14142 \\
(59.6)\end{array}$ & $\begin{array}{l}4234 \\
(55.6)\end{array}$ & $\begin{array}{l}7964 \\
(61.2)\end{array}$ & $\begin{array}{l}4584 \\
(57.9)\end{array}$ & $\begin{array}{l}1170 \\
(57.2)\end{array}$ & 29.042 & $<0.001$ \\
\hline$>4$ & $\begin{array}{l}8957 \\
(37.8)\end{array}$ & $308(40.4)$ & $\begin{array}{l}4726 \\
(36.3)\end{array}$ & $\begin{array}{l}3104 \\
(39.2)\end{array}$ & $819(40.0)$ & & \\
\hline $\begin{array}{l}\text { Missing } \\
\text { value } \\
\text { Type of } \\
\text { fertiliza- } \\
\text { tion in } \\
\text { current } \\
\text { cycle }\end{array}$ & $627(2.6)$ & $31(4.1)$ & $314(2.4)$ & $225(2.8)$ & $57(2.8)$ & & \\
\hline IVF & $\begin{array}{l}12113 \\
(51.1)\end{array}$ & $437(57.3)$ & $\begin{array}{l}7074 \\
(54.4)\end{array}$ & $\begin{array}{l}3458 \\
(43.7)\end{array}$ & $\begin{array}{l}1144 \\
(55.9)\end{array}$ & 296.204 & $<0.001$ \\
\hline ICSI & $\begin{array}{l}10574 \\
(44.6)\end{array}$ & 304 (39.9) & $\begin{array}{l}5423 \\
(41.7)\end{array}$ & $\begin{array}{l}4075 \\
(51.5)\end{array}$ & $771(37.7)$ & & \\
\hline $\begin{array}{l}\text { IVF+ICSI } \\
\text { Previous } \\
\text { ART } \\
\text { cycles }\end{array}$ & $\begin{array}{l}1039(4.4) \\
3(2,4)\end{array}$ & $\begin{array}{l}21(2.8) \\
2(1,3)\end{array}$ & $\begin{array}{l}507(3.9) \\
1(1,2)\end{array}$ & $\begin{array}{l}380(4.8) \\
2(1,3)\end{array}$ & $\begin{array}{l}131(6.4) \\
2(2,4)\end{array}$ & & \\
\hline 0-1 cycles & $\begin{array}{l}10710 \\
(45.1)\end{array}$ & $217(28.5)$ & $\begin{array}{l}6307 \\
(48.5)\end{array}$ & $\begin{array}{l}3727 \\
(47.1)\end{array}$ & $458(22.4)$ & 768.355 & $<0.001$ \\
\hline 2-3 cycles & $\begin{array}{l}8590 \\
(36.2)\end{array}$ & $328(43.0)$ & $\begin{array}{l}4538 \\
(34.9)\end{array}$ & $\begin{array}{l}2754 \\
(34.8)\end{array}$ & $970(47.4)$ & & \\
\hline 4-5 cycles & $2185(9.2)$ & $85(11.2)$ & $923(7.1)$ & $831(10.5)$ & $346(16.9)$ & & \\
\hline
\end{tabular}




\begin{tabular}{|c|c|c|c|c|c|c|c|}
\hline & $\begin{array}{l}\text { All FET } \\
\text { cycles } \\
(n=23726)\end{array}$ & $\begin{array}{l}\text { Single } \\
\text { cleavage- } \\
\text { stage } \\
\text { embryo } \\
\text { transfer } \\
\text { group } \\
(\mathrm{C}-1) \\
(\mathrm{n}=763)\end{array}$ & $\begin{array}{l}\text { Double } \\
\text { cleavage- } \\
\text { stage } \\
\text { embryo } \\
\text { transfer } \\
\text { group } \\
(\mathrm{C}-2) \\
(\mathrm{n}=13004)\end{array}$ & $\begin{array}{l}\text { Single } \\
\text { blastocyst- } \\
\text { stage } \\
\text { embryo } \\
\text { transfer } \\
\text { group } \\
(\mathrm{B}-1) \\
(\mathrm{n}=7913)\end{array}$ & $\begin{array}{l}\text { Double } \\
\text { blastocyst- } \\
\text { stage } \\
\text { embryo } \\
\text { transfer } \\
\text { group } \\
(\mathrm{B}-2) \\
(\mathrm{n}=2046)\end{array}$ & $\mathbf{X}^{2}$ & $\mathbf{P}$ \\
\hline [?]6 cycles & $804(3.4)$ & $49(6.4)$ & $299(2.3)$ & $317(4.0)$ & $139(6.8)$ & & \\
\hline $\begin{array}{l}\text { Missing } \\
\text { value } \\
\text { Maternal } \\
\& \\
\text { Neonatal } \\
\text { Out- } \\
\text { comes }\end{array}$ & $1437(6.1)$ & $83(10.9)$ & $936(7.2)$ & $285(3.6)$ & $133(6.5)$ & & \\
\hline $\begin{array}{l}\text { Biochemical } \\
\text { pregnancy }\end{array}$ & $\begin{array}{l}11427 \\
(48.2)\end{array}$ & $184(24.1)$ & $\begin{array}{l}6077 \\
(46.7)\end{array}$ & $\begin{array}{l}3957 \\
(50.0)\end{array}$ & $\begin{array}{l}1209 \\
(59.1)\end{array}$ & 296.037 & $<0.001$ \\
\hline $\begin{array}{l}\text { Clinical } \\
\text { pregnancy }\end{array}$ & $\begin{array}{l}10237 \\
(43.1)\end{array}$ & $164(21.5)$ & $\begin{array}{l}5481 \\
(42.1)\end{array}$ & $\begin{array}{l}3507 \\
(44.3)\end{array}$ & $\begin{array}{l}1085 \\
(53.0)\end{array}$ & 237.023 & $<0.001$ \\
\hline $\begin{array}{l}{ }^{*} \text { Monozygotic } \\
\text { twins }\end{array}$ & $151(1.5)$ & $3(1.8)$ & $47(0.9)$ & $79(2.3)$ & $22(2.0)$ & $31.668^{@}$ & $<0.001^{@}$ \\
\hline *Miscarriage & $\begin{array}{l}1687 \\
(16.5)\end{array}$ & $39(23.8)$ & $786(14.3)$ & $632(18.0)$ & $230(21.2)$ & 48.180 & $<0.001$ \\
\hline $\begin{array}{l}{ }^{*} \text { Maternal } \\
\text { complication }\end{array}$ & $968(9.5)$ & $12(7.1)$ & $515(9.4)$ & $312(8.9)$ & $129(11.9)$ & 9.686 & 0.021 \\
\hline Live birth & $\begin{array}{l}6368 \\
(26.8)\end{array}$ & $90(11.8)$ & $\begin{array}{l}3771 \\
(29.0)\end{array}$ & $\begin{array}{l}1819 \\
(23.0)\end{array}$ & $688(33.6)$ & 226.611 & $<0.001$ \\
\hline $\begin{array}{l}{ }^{[?]} \text { Twin } \\
\text { birth }\end{array}$ & $\begin{array}{l}1116 \\
(17.5)\end{array}$ & $0(0.0)$ & $883(23.4)$ & $34(1.9)$ & $199(28.9)$ & 479.969 & $<0.001$ \\
\hline $\begin{array}{l}{ }^{[?]} \text { Preterm } \\
\text { birth }\end{array}$ & $936(14.7)$ & $6(6.7)$ & $609(16.1)$ & $175(9.6)$ & $146(21.2)$ & 71.715 & $<0.001$ \\
\hline $\begin{array}{l}{ }^{[?]} \text { Low } \\
\text { birth } \\
\text { weight }\end{array}$ & $776(12.2)$ & $3(3.3)$ & $559(14.8)$ & $92(5.1)$ & $122(17.7)$ & 137.261 & $<0.001$ \\
\hline${ }^{[?]} \mathrm{SGA}$ & $362(5.7)$ & $4(4.4)$ & $267(7.1)$ & $55(3.0)$ & $36(5.2)$ & 38.245 & $<0.001$ \\
\hline
\end{tabular}

Notes: Values are n (\%) or median (1st quartile, 3rd quartile). ${ }^{*}$ The denominator is the number of clinical pregnancies in each group. [?] The denominator is the number of live births in each group. @ Likelihood Ratio for the case that one or more cells has expected count less than 5. 

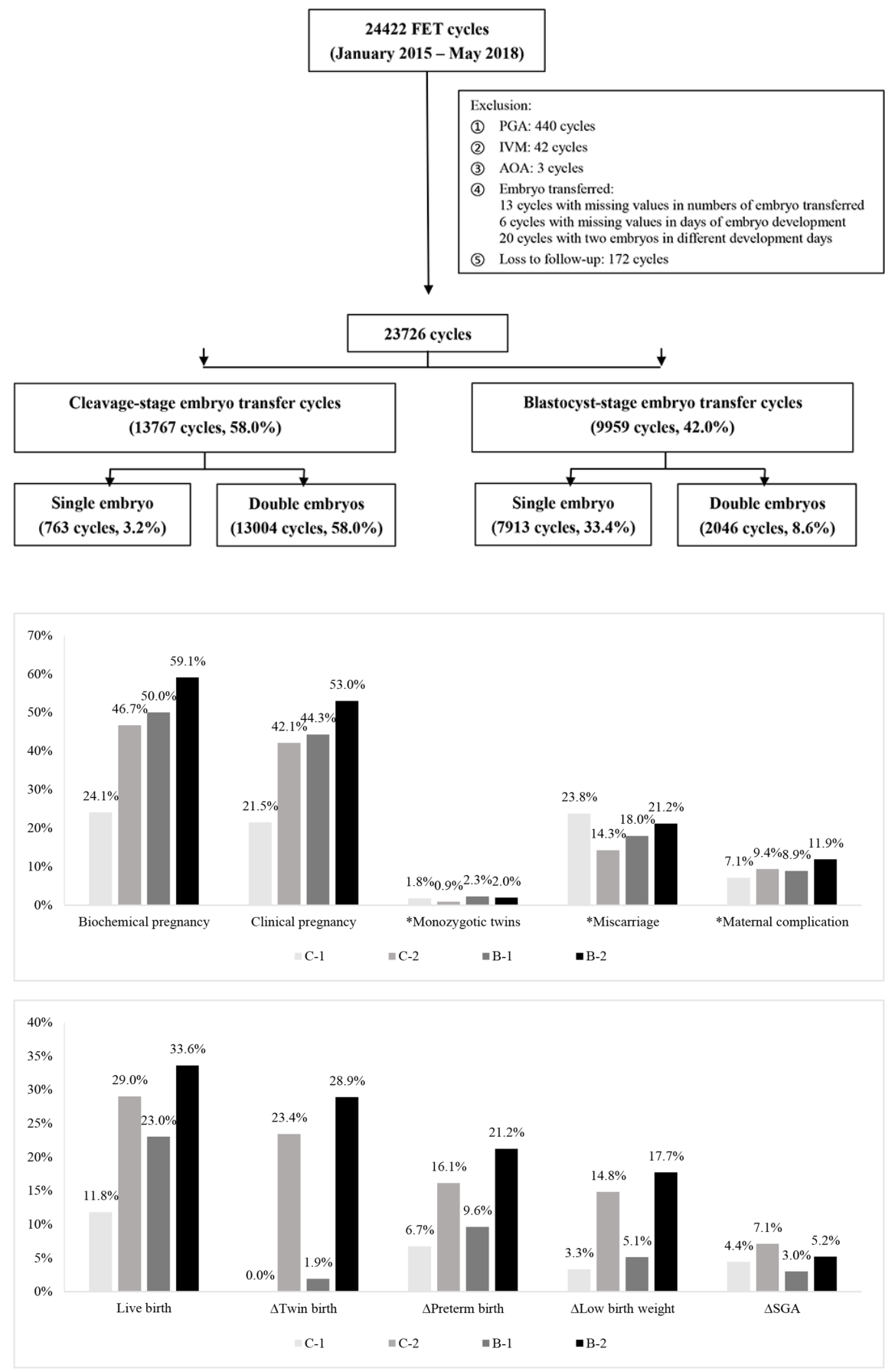


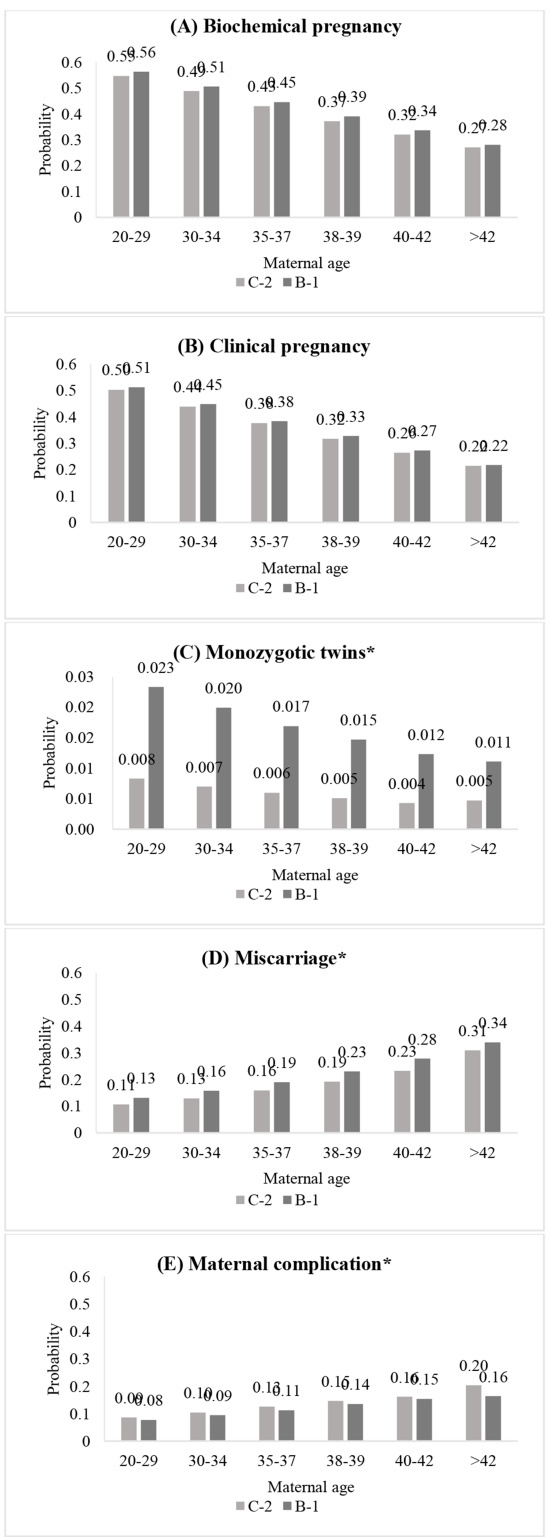

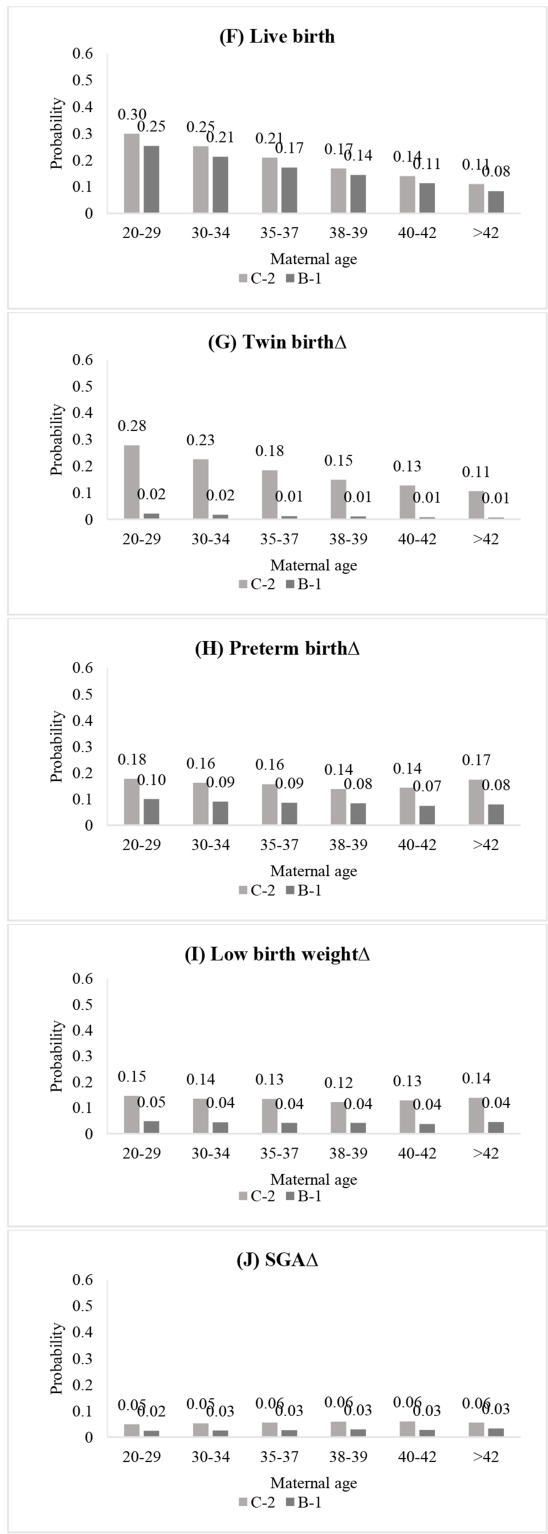

